\title{
OSTEOSYNTHESIS OF THE FRACTURED FIFTH METATARSUS WITH HEADLESS SCREW
}

\author{
K. Šimečková*, K. Frydrýšek ${ }^{* *}$, V. Machalla***, J. Demel ${ }^{* * * *}$, L. Pleva ${ }^{* * * * * *}$, V. Bajtek ${ }^{* * * * * * *}$
}

\begin{abstract}
This article focuses on a fixative implant, namely a headless (Herbert) screw, designed for minimally invasive osteosynthesis of the $5^{\text {th }}$ metatarsus. An original experiment is conducted in which the axial compression forces applied to the headless screw are measured and evaluated during osteosynthesis of the bone fragment in the laboratory. The information gathered fills in gaps in the knowledge of the measured quantities. The results of the experiment that have been made on porcine bones are compared with calculations using an analytical solution of a statically indeterminate task in compression.
\end{abstract}

Keywords: headless (Herbert) screw, $5^{\text {th }}$ metatarsus, osteosynthesis, experiments, analytical approach.

\section{Introduction}

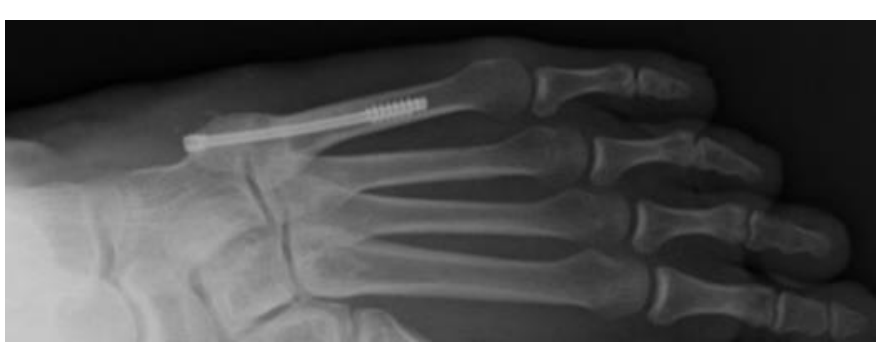

Fig. 1: Radiograph of the fracture of the base of the $5^{\text {th }}$ metatarsus after osteosynthesis by Herbert screw.

Osteosynthesis is an operative method for the treatment of complicated fractures consisting in fixation of bone fragments by means of implants (screws, splints, nails, wires, external fixators, etc.). These implants are introduced into the body temporarily or permanently. In our case, the fixation of the fracture by a headless screw is achieved by its design, due to the different pitch of the threads in the terminal threaded parts. This results in the mutual compression (tightening) of the fragments of the bone and subsequent healing. The most common leg fractures are metatarsal fractures, and the most common type of these fractures are those of the $5^{\text {th }}$ metatarsus, see Fig. 1, wherein the fixation of the fracture of the $5^{\text {th }}$ metatarsus is performed by a Herbert type headless screw. These are the fractures of the base of the $5^{\text {th }}$ metatarsus,

* MSc. Kateřina Šimečková: Faculty of Mechanical Engineering, VSB - Technical University of Ostrava, 17. listopadu 2172/15, 70800 Ostrava-Poruba, CZ, katerina.simeckova@vsb.cz

** Assoc. Prof. Karel Frydrýšek, Ph.D., ING-PAED IGIP: Faculty of Mechanical Engineering,VSB - Technical University of Ostrava, 17. listopadu 2172/15, 70800 Ostrava-Poruba, CZ, karel.frydrysek @ vsb.cz

*** MSc. Vojtěch Machalla: Faculty of Mechanical Engineering, VSB - Technical University of Ostrava, 17. listopadu 2172/15, 70800 Ostrava-Poruba, CZ, vojtech.machalla@ vsb.cz

**** M.D. Jiř́ Demel: Trauma Centre, University Hospital in Ostrava and Faculty of Medicine, 17. listopadu 1790, 70800 Ostrava-Poruba, CZ, jiri.demel@osu.cz

******Assoc. Prof. M.D. Leopold Pleva, Ph.D.: Trauma Centre, University Hospital in Ostrava and Faculty of Medicine 17. listopadu 1790, 70800 Ostrava-Poruba, CZ, leopold.pleva@ osu.cz

******** MSc. Vojtěch Bajtek: Faculty of Mechanical Engineering,VSB - Technical University of Ostrava, 17. listopadu 2172/15, 70800 Ostrava-Poruba, CZ, vojtech.bajtek@ vsb.cz 
which are most common amongst professional athletes (basketball, volleyball). The surgical treatment of these fractures improves their treatment and allows young athletes to return to the training process as soon as possible (Demel, 2004).

\section{Progress of the experiment}

The aim of the experiment was to determine the progress of the axial force acting on the headless selfcutting cannulated titanium alloy screw Ti; $4,0 / 1,4 \times 30 / 7 \mathrm{~mm}$ manufacture by MEDIN, a.s. This screw, shown in Fig. 2 (a), is made of titanium alloy Ti6Al4V, the properties of which are specified by the standard ISO 5832-3 (material for surgical implants). Knowledge of axial forces is an important element in the design and optimization of headless screws and their threads. In addition, there is insufficient information on such types of measurements in the literature (Šimečková, 2018).
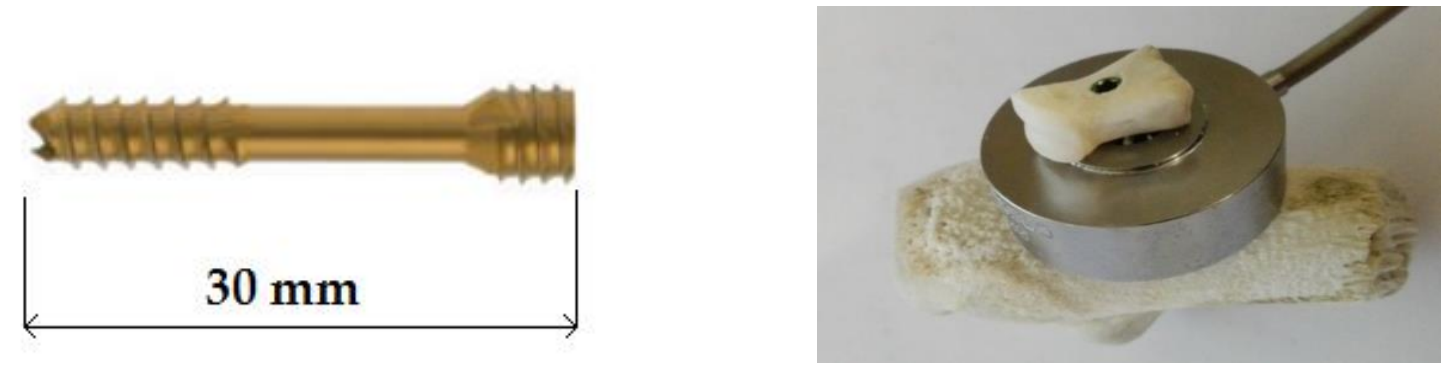

Fig. 2: (a) Dimensions of Headless Bone Screw; (b) Measurement (bone fragments, screw and sensor)

Using a strain gauge pressure sensor with an opening of LC 8150-375-500 type (see Fig. 2 (b)), the Vishay P-3500 strain indicator and the KRAFTWERK torque screwdriver, the axial compression forces applied to the headless screw during tightening were measured. The progress of the experiment was carried out in accordance with the surgical procedure. The experiment was performed on the headless screw introduced into the porcine leg bones. The porcine bone was used as an easily accessible and similar substitute for human metatarsus. Ten measurements were performed as a part of this research. The screw is tightened at a tightening torque of $2.5 \mathrm{Nm}$. Measurement of the force was carried out after the quarter of a turn of the screw until the headless screw was tightened to 3.5 turns and included the moment in which the thread in the bone is stripped (bone thread stripping - unsuccessful osteosynthesis).

\section{Experiment results}

All 10 measurements were statistically processed. The dependencies of the arithmetic mean, median, minimum and maximum of the compressive force $F[\mathrm{~N}]$ on the tightening turns of the Herbert screw $n$ [1] were determined. These dependencies are shown in Fig. 3 and 4 (for measurements $1-5$ and 6 - 10) and Tab. 1.

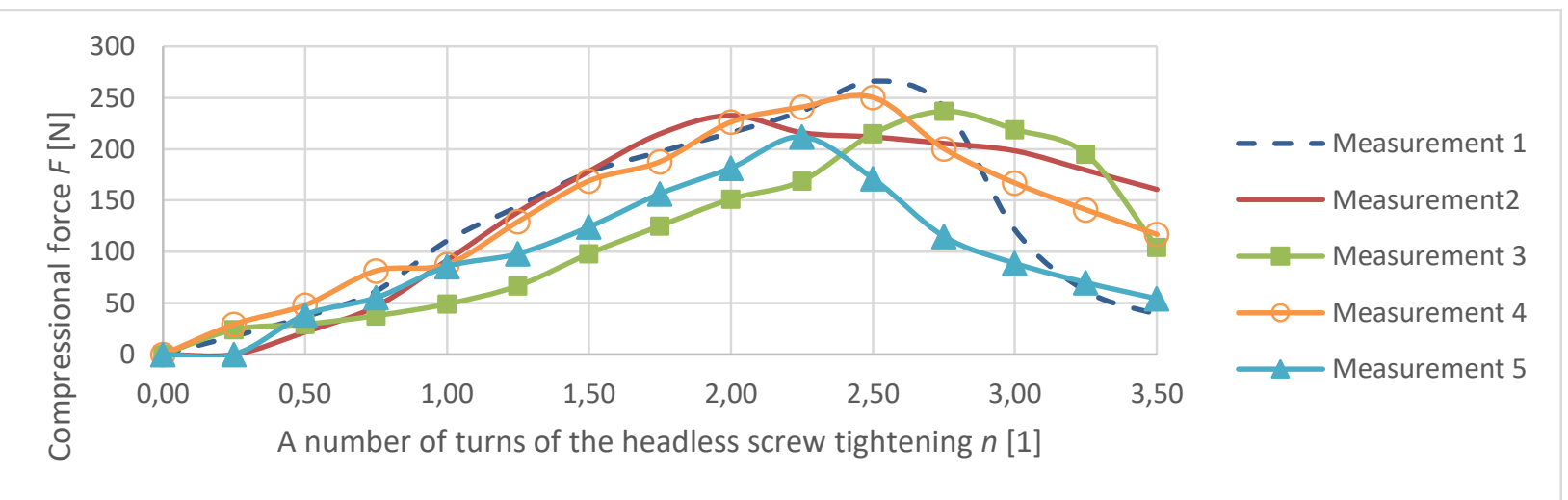

Fig. 3: Axial Force (measurement 1-5) 


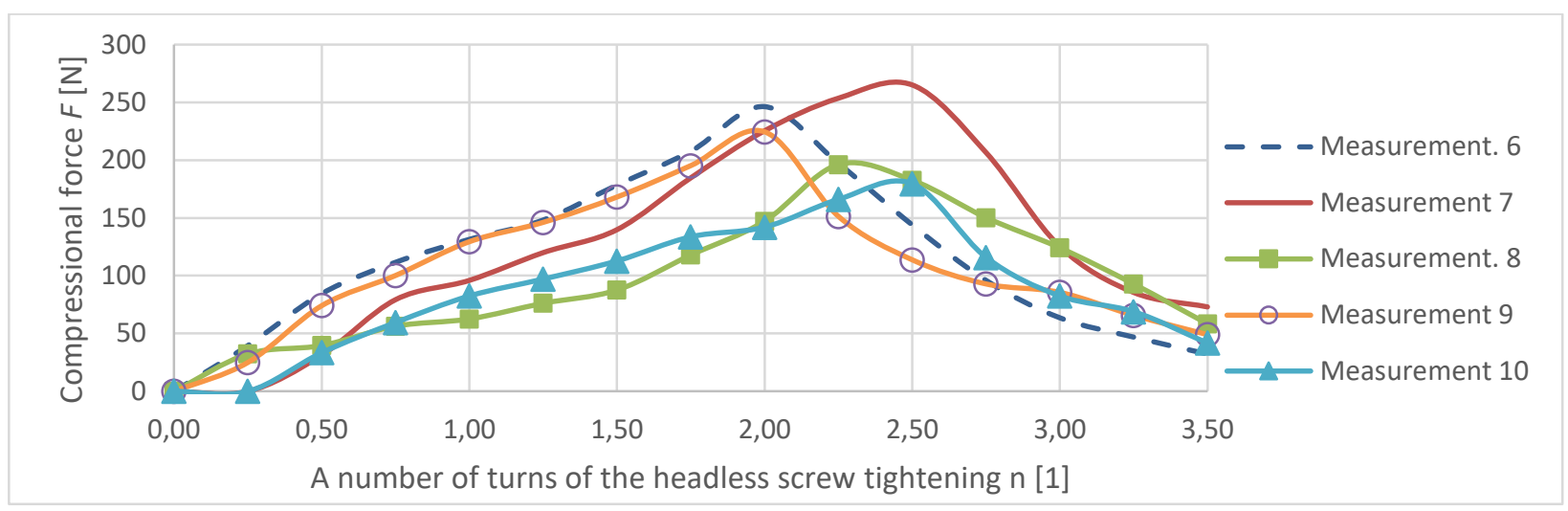

Fig. 4: Axial Force (measurement 6-10)

Tab. 1: Maximal measured values of axial forces.

\begin{tabular}{|c|c|c|c|c|c|c|c|c|c|c|c|c|}
\hline Measurement & $\mathbf{1}$ & $\mathbf{2}$ & $\mathbf{3}$ & $\mathbf{4}$ & $\mathbf{5}$ & $\mathbf{6}$ & $\mathbf{7}$ & $\mathbf{8}$ & $\mathbf{9}$ & $\mathbf{1 0}$ & $\begin{array}{c}\text { Mean } \\
\text { (from } \\
\text { Fig. 5) }\end{array}$ & $\begin{array}{c}\text { Median } \\
\text { (from } \\
\text { Fig. 5) }\end{array}$ \\
\hline Fmax $[\mathbf{N}]$ & 266 & 233 & 237 & 250 & 212 & 246 & 265 & 196 & 224 & 180 & 204 & 220 \\
\hline $\boldsymbol{n}[\mathbf{1}]$ & 2.5 & 2 & 2.75 & 2.5 & 2.25 & 2 & 2.5 & 2.25 & 2 & 2.5 & 2.25 & 2 \\
\hline
\end{tabular}

Fig. 5 shows the course of the arithmetic mean and the median curve. The maximum and minimum force measurements constitute the envelope of the compression force dependency progress $F$. The highest average compressive force is $204 \mathrm{~N}$ and acts on the screw when tightened to 2.25 turns, then the thread is stripped in the bone and the compression force begins to decrease. The highest median value of the axial compressive force acts on the screw at 2 turns of tightening and its value is $220 \mathrm{~N}$. It follows from the data that the safe limit for tightening the screw is 1.75 turns, which is the extreme value where no thread stripping has taken place at any measurements (i.e. important recommendations for physicians).

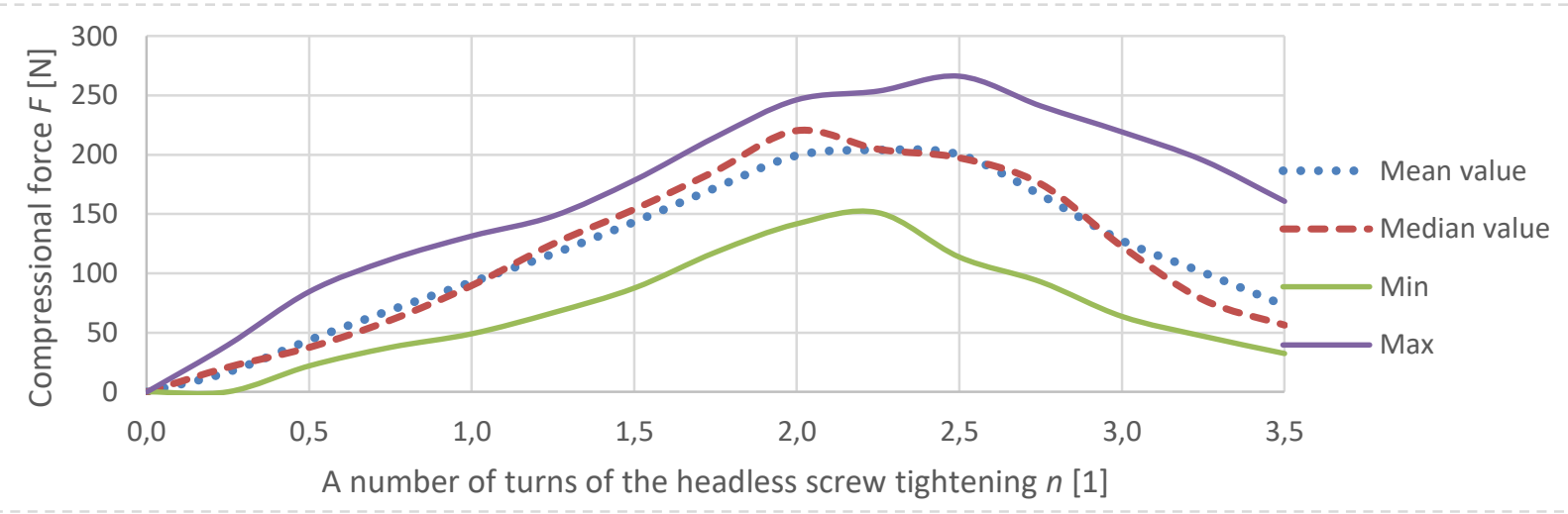

Fig. 5: Statistics of Axial Force

\section{Comparison of measured values and analytical solutions}

This task was also solved as $1 \times$ statically indeterminate compression task, assuming small deformations and using isotropic material (Šimečková, 2018). Normal force $\mathrm{F}$ for $n=1.75$ of tightening turns was calculated as:

$$
F=\frac{\Delta}{\frac{L_{k 1}}{E_{k} \cdot A_{k 1}}+\frac{1}{E_{k}}\left(\frac{L_{b}}{A_{k 3}}+\frac{L_{k 2}-L_{b}}{A_{k 2}}\right)+\frac{1}{E_{1}}\left(\frac{L_{a}}{A_{a}}+\frac{L_{b}}{A_{b}}+\frac{L_{c}}{A_{c}}\right)+a_{S}}=164.3 \mathrm{~N} .
$$

The meaning of each variable is given in Tab. 2. Comparison of the analytically calculated and measured normal force is also shown in Fig. 6. The figure shows that there is no significant variation in the analytical solution and measurement in the linear elastic region up to the tightening torque turns of the screw of 1.75 , i.e. the thread is not stripped. 
Tab. 2: Definition of quantities (Šimečková, 2018)

\begin{tabular}{|c|l|c|l|}
\hline Quantity & \multicolumn{1}{|c|}{ Definition of quantity } & Quantity & \multicolumn{1}{|c|}{ Definition of quantity } \\
\hline$L_{k 1}, L_{k 2}$ & Lengths of bone fragments & $\Delta$ & $\begin{array}{l}\text { Mutual displacement of the first bone } \\
\text { fragment in respect of the second bone } \\
\text { fragment after tightening }\end{array}$ \\
\hline$A_{k 1}, A_{k 2}, A_{k 3}$ & $\begin{array}{l}\text { Bone areas in individual parts of } \\
\text { the screw }\end{array}$ & $E_{k}$ & Modulus of tensile elasticity of the bone \\
\hline$A_{a}, A_{b}, A_{c}$ & Screw areas in individual parts & $E_{1}$ & Modulus of tensile elasticity of the screw \\
\hline$L_{a}, L_{b}, L_{c}$ & Screw lengths in individual parts & $a_{S}$ & Effect of the force sensor \\
\hline
\end{tabular}

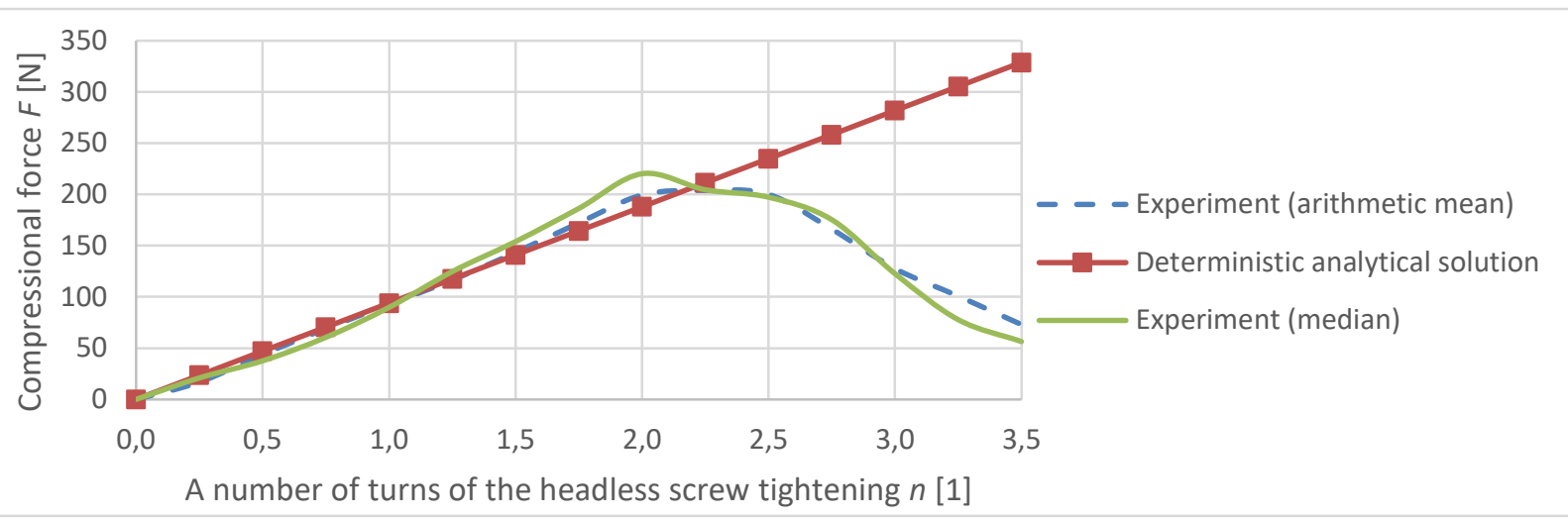

Fig. 6: Comparison of Measurement and Analytical Calculation

In Šimečková (2018) there is also an important stochastic solution of the problem using the Monte Carlo method, which is however not the subject of this article.

\section{Conclusions}

The main objective was to carry out an experimental analysis associated with the determination of axial force in osteosynthesis of $5^{\text {th }}$ metatarsus with a headless screw (Ti;4.0/1.4x30/7 mm by MEDIN a.s.), which is intended to fix the $5^{\text {th }}$ metatarsal fracture. Such fixation implants are commonly used in medical practice. It was found that the safe number of the tightening turns for this screw is 1.75 . This value corresponds to the arithmetic mean of the measured axial force of $172 \mathrm{~N}$ or to the analytical calculated 164.3 N. The results obtained, similarly to the equivalent tasks solved in our facility, serve as testimonials for clinical tests, see e.g. Frydrýšek, 2018.

\section{Acknowledgement}

The authors gratefully acknowledge the funding from the project SP2019/100 "Use of numerical and experimental modeling in industrial practice" and the project No.CZ.02.1.01/0.0/0.0/17_049/0008441 "Innovative therapeutic methods of musculoskeletal system in accident surgery" within the Operational Programme Research, Development and Education financed by the European Union and from the state budget of the Czech Republic and the project Innovative and additive manufacturing technology-new technological solutions for 3D printing of metals and composite materials, reg. no. CZ.02.1.01/0.0/17_049/0008407 financed by Structural Founds of Europe Union.

\section{References}

Šimečková, K. (2018) Biomechanics: Implants in traumatology and orthopedics. Diploma thesis, pp. 71, VŠBTUO, Ostrava.

Frydrýšek, K, Šír, M., Pleva, L. (2018) Strength Analyses of Screws for Femoral Neck Fractures, Journal of medical and biological engineering, Vol. 38, Issue:5, pp. 816-834, DOI:10.1007/s40846-018-0378-x

Demel, J. Pleva L. (2004) Treatment of Jones fracture by Herebrt screw, Úrazová chirurgie, 2004, Vol II, ISSN 1211-7080. 